\title{
Fixation of Middle Third Humeral Shaft Fractures by Anteromedial Plate Through Anterolateral Approach
}

\author{
MOHAMMED A. REZK, M.Sc.; AYMAN E. KHALIL, M.D.; ASHRAF A. MAHMOUD, M.D. and \\ MOHAMMED A. ROMEIH, M.D.
}

The Department of Orthopaedic Surgery, Faculty of Medicine, Tanta University

\begin{abstract}
Background: Treatment of humeral shaft fractures has been a subject of debate for many decades. Even though a large majority of humeral shaft fractures can be treated by non operative methods, few conditions like open fractures, polytrauma, ipsilateral humeral shaft and forearm fractures require surgical intervention. The goal of treatment of humeral shaft fractures is to establish union with an acceptable humeral alignment and to restore the patient to pre-injury level of function. The objective was to assess the incidence of radial nerve palsy, non-union and mean time required for in anteromedial plate osteosynthesis with anterolateral approach and also to measure the functional outcome of this procedure.
\end{abstract}

Aim of Study: The aim of this study is evaluation of results of fixation of middle third of humeral shaft fractures by anteromedial plate osteosynthesis through an anterolateral approach.

Patients and Methods: In this prospective study, 21 cases with middle third humeral shaft fractures were treated with anteromedial plate through anterolateral approach. Clinical and radiological data were analyzed.

Results: These cases were assessed according to Murphy scoring systems for middle third humerus fracture the clinical results were graded as excellent in 14 patients $(66.6 \%)$, good in 4 patients $(19 \%)$, fair in 3 patients $(14.3 \%) \&$ poor in no patients $(0 \%)$. The excellent and good results were considered as satisfactory results, while the unsatisfactory included the fair and the poor results. Thus, satisfactory results were found in 18 patients $(85.7 \%)$, and the unsatisfactory results were found in 3 patients $(14.3 \%)$.

Conclusion: This study proves that anteromedial plating of middle shaft humerus through anterolateral approach is safe, effective and avoids release of deltoid tendon insertion and also avoids radial nerve dissection and its injury.

Key Words: Humeral shaft fractures - Anteromedial plateAnterolateral approach.

\section{Introduction}

FRACTURES of humeral shaft are commonly encountered by orthopedic surgeons accounting

Correspondence to: Dr. Mohammed A. Rezk, The Department of Orthopaedic Surgery, Faculty of Medicine, Tanta University for approximately $3 \%$ of all fractures, which result in significant burden to society, the goal of treatment is to establish union with an acceptable humeral alignment and to restore the patient to preinjury level of function $[\mathbf{1 , 2}]$.

Operative treatment is required in conditions like open fractures, poly-trauma and in cases in which there is failure of conservative treatment, bilateral humeral fractures, floating elbow, intraarticular fracture extension, progressive nerve palsy or nerve palsy after closed manipulation and vascular injury [2] .

Surgical management includes plate osteosynthesis, intra-medullary nailing or external fixation. Plate osteosynthesis remains the gold standard for the operative fixation of humeral shaft fractures despite advances in implant technology [2]

The incidence of postsurgical radial nerve palsy ranges from $0 \%$ to $5.1 \%$ [6]. The causes of radial nerve palsy include manipulation of the nerve during surgery, impingement between fracture fragments, entrapment by fracture callus and tissue scar formation [2] .

The anteromedial surface of the shaft of the humerus is smooth than the antero lateral surface that makes medial plating more suitable, also antero medial plating is thought to decrease the rate of radial nerve injury and avoid release of deltoid insertion.

\section{Patients and Methods}

\section{A- Patients:}

This study this study included 21 patients with recent middle third humerus fractures treated between August 2017 and October 2018 (including follow-up period) at Tanta University Hospital. 
The period of follow-up ranged from 6 month to 12 months with an average of 8 months.

\section{Clinical examination:}

\section{General examination:}

Blood pressure, pulse, temperature, respiration other body systems. Associated injuries.

\section{Local examination:}

- A- Inspection: Deformity, skin condition and presence of wound or associated injuries.

- B- Palpation: Localized bony tenderness and abnormal mobility at fracture site.

- C- Neurovascular examination.

The inclusion criteria were patient more than 18 years old, recent fracture within 2 weeks after trauma, closed or open fractures grade I, floating elbow. While, the main exclusion criteria were patients less than 18 years old, pre-operative radial nerve palsy, un united fracture, open fractures grade II, III, pathological fracture.

\section{B- Method:}

Surgical steps: Pre-operative antibiotics were given to all the patient.

Surgical procedure: The patients were placed on supine position on an operating table with the arm in abduction on arm board after induction of general anesthesia.

- The entire limb was prepared exposing both shoulder and elbow Fig. (1).

- The humerus was approached by the standard Henry's approach. The incision was made along the lateral border of biceps with sufficient length to allow insertion of the plate, the space between biceps and brachialis was identified and the musculocutaneous nerve was visualized and protected. The biceps was retracted medially and the brachialis muscle was splitted longitudinally to expose the humerus, the arm was externally rotated to facilitate the visualization of the anteromedial surface of the humerus. Figs. (1A,B,C,D).

- Reduction of the fracture and plate fixation on the anteromedial surface.

- Haemostasis and closure of the wound and drain insertion.

- Immediate post-operative radiograph was taken.

- Patient was assessed clinically and radio logically every month till recovery.

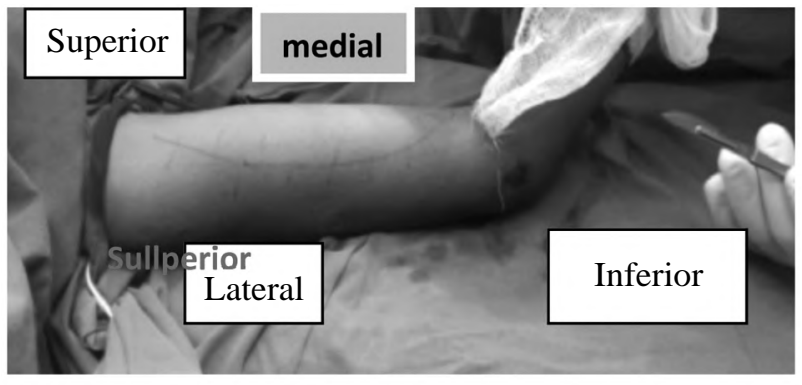

Fig. (1A): Arm preparation.

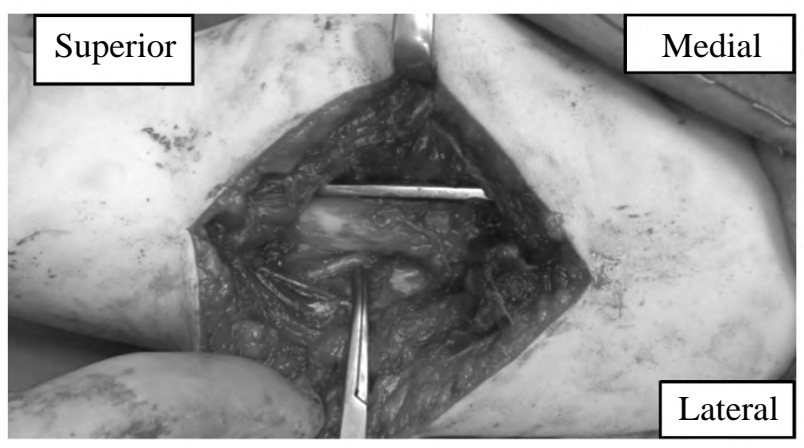

Fig. (1B): Intra operative photo during reduction and plate application.

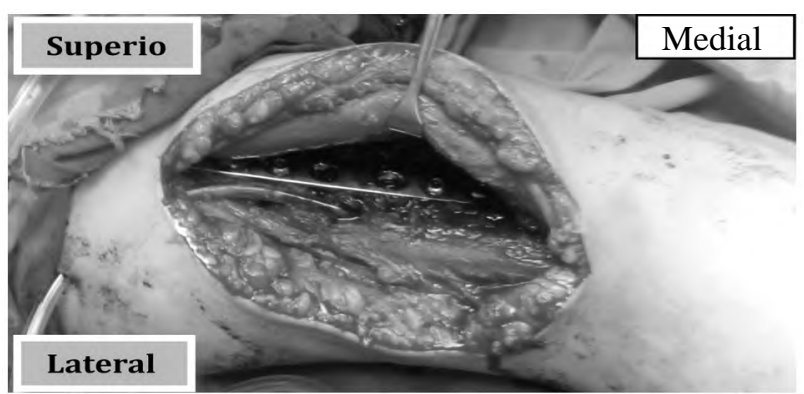

Fig. (1C): Intra operative photo: Plate fixation complete.

\section{Post-operative period:}

\section{Post-operative:}

A pouch arm sling is used and two days postoperative the suction was removed, the wound was inspected and sterile dressing was applied. Also, guraded active movement were encouraged from the $3^{\text {rd }}$ day to avoid elbow and shoulder stiffness, putting in consideration the damage to soft tissue, either as result of trauma or due to surgery. Also the security of fixation was taken into consideration.

Two weeks post-operative stitches was removed. Follow-up:

The cases were followed-up to 6 months from time of surgery.

The follow-up include pain during rest, activity the ability to ordinary activities and range of movement of elbow joint.

The radiological follow-up included X-rays every month. 


\section{Results}

In this prospective study, 21 cases with recent middle third humeral fractures were operated through anterolateral approach with anteromedial plating. Clinical and radiological data were analyzed.

\section{Operative time:}

Operative time ranged between 60 and $90 \mathrm{~min}$ utes with a mean of \pm 75 minutes. The minimal time was in cases with less comminuation that had easy reduction. It increased gradually in cases with more comminuted fractures and difficult reduction.

\section{Follow-up period:}

Follow-up period ranged from 6 to 12 months with a mean of $8.6 \pm 1.2$ months. The patients were followed-up until they achieved complete fracture healing and almost normal arm function.

\section{Clinical (functional) results:}

According to Murphy scoring systems for middle third humerus fracture the clinical results were graded as excellent in 14 patients $(66.6 \%)$, good in 4 patients (19\%), fair in 3 patients $(14.3 \%) \&$ poor in no patients $(0 \%)$. The excellent and good results were considered as satisfactory results, while the unsatisfactory included the fair and the poor results. Thus, satisfactory results were found in 18 patients $(85.7 \%)$, and the unsatisfactory results were found in 3 patients $(14.3 \%)$.

Pain, range of movement, range motion, return to previous activity:

By the end of the follow-up period 20 patients (95.2\%) had no pain at all patients $(4.8 \%)$ had mild occasional pain. All patients developed full range elbow and returned rapidly to their normal daily activity. Radiological assessment according to Xray after 1.5 month, 3 months and 6 months. Fracture in 18 patient was united within 3 months and fracture in 3 patient was united within 6 months, all of them were old age over 50 years old, one of them was obese and diabetic and one of them was smoker.

Factors affecting the final clinical score:

1-Age: Results showed to be statistically significant, as $p$-value $=0.0022$.

2- Smoking and functional end results: Studying the relation between smoking and the final end results showed to be statistically significant, as $p$-value $=0.0090$.

3- Sex and functional end results: Studying the relation between smoking and the final end results showed to be statistically insignificant, as $p$-value $=0.9063$.

4- Shape of fracture and functional end results: Studying the relation between shape of fracture and the final results showed it to be statistically insignificant, as $p$-value $=0.1489$.

5-Mode of trauma and the functional end results: Studying the relation between patient's mode of trauma and the final results showed it to be statistically insignificant, as $p$-value $=0.4421$.

6- Occupation and the functional end results: Studying the relation between patient's occupation and the final results showed it to be statistically insignificant as $p$-value $=0.4594$.

7- Side and the functional end: Studying the relation between side of injury and the final results showed it to be statisticall insignificant, $p$-value $=$ 0.5250 .

8- Obesity and the functional end results: Studying the relation between obesity and the final results showed it to be statistically insignificant, $p$ value $=0.3971$.

9- Relation between medical comorbidity and end result: Studying the relation between medical comorbidity and the final results showed it to be statistically insignificant $p$-value $=0.0429$.

A house wife aged 35 years old. She was presented with right side a closed mid shaft oblique humeral fracture due to road traffic accident. She had no medical history and was neurologically intact. Union occurred within 3 months after surgery with no pain and full range of motion. She also returned to her normal daily activities. She had an excellent functional score.

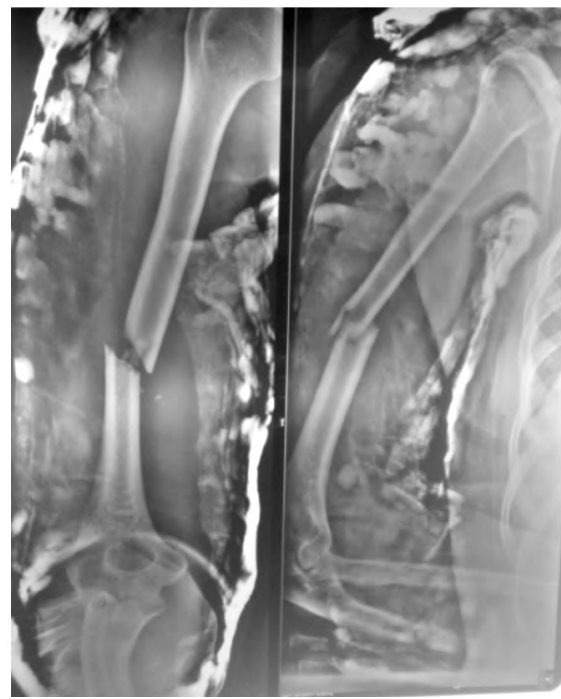

Fig. (2A): Pre-operative X-ray: Antero posterior and lateral view. 


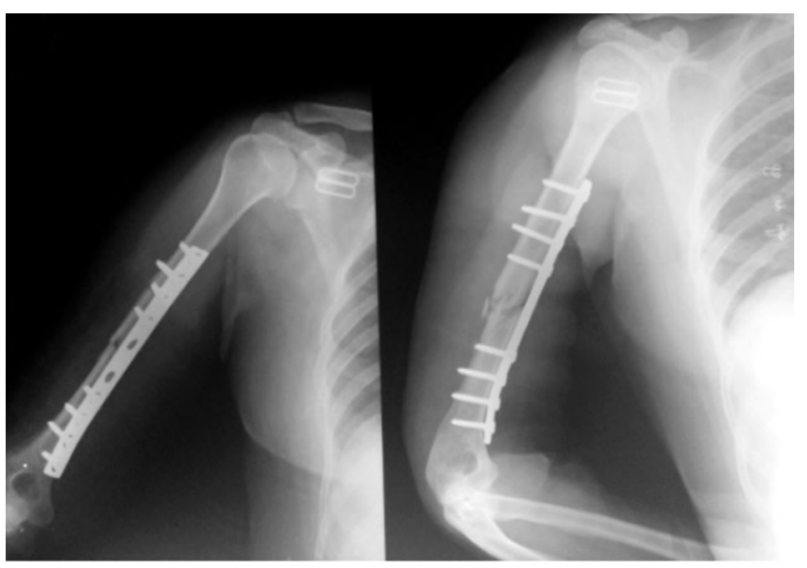

Fig. (2B): Immediate post X-ray: Ap and lateral view.

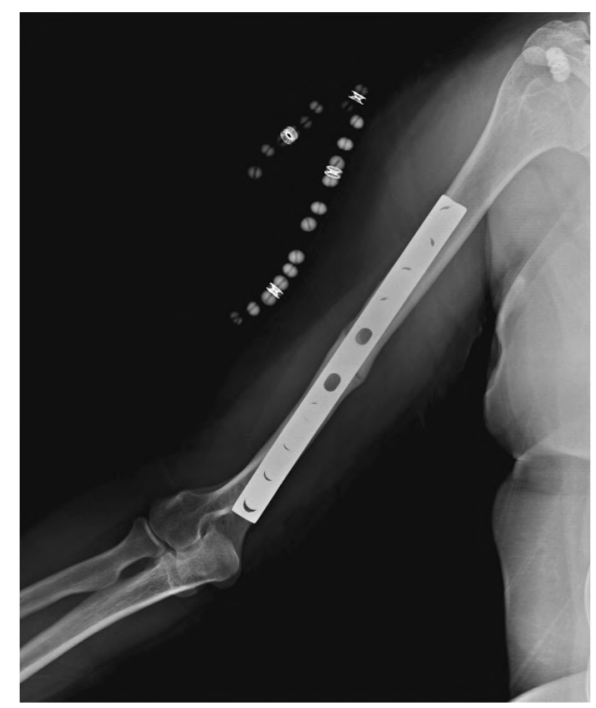

Fig. (2C): Follow-up X-ray after 3 month (AP view).

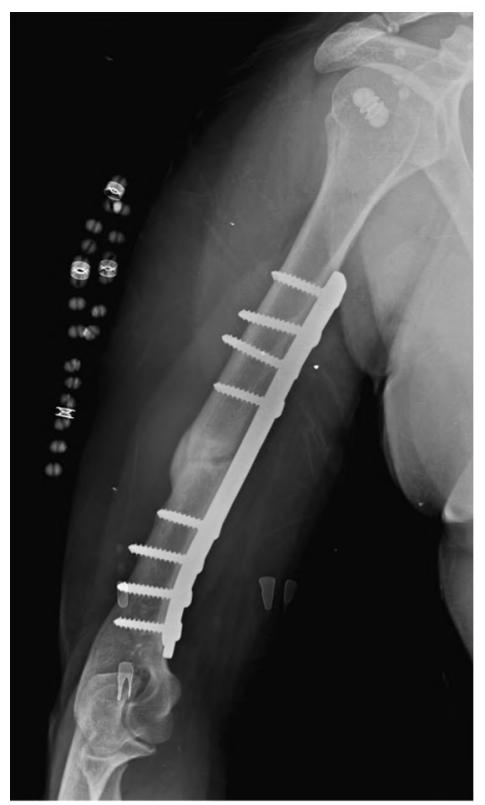

Fig. (2D): Follow-up X-ray after 3 month (lateral view).

\section{Discussion}

The humerus itself is a cylinder proximally, which provides strength and resistance to both torsional and bending forces, and distally it tapers to a triangular shape. It is enveloped in muscle and soft tissue, hence the favorable prognosis for healing in uncomplicated fractures [1-4].

Antero medial plating of humerus is thought to decrease the rate of radial nerve injury, avoid release of deltoid insertion and to fix the plate on a rather smooth surface [4-10].

So fixation of fracture middle third humerus has a lot of advantages like saving radial nerve with minimal complication with less time and soft tissue injury. Also many studies reported that this maneuver is biomechanically better for fixation as on exposure of humerus regarding to all mechanical tests as horizontal torsional, axial compressive fatigue test, four point bending fatigue test in anteroposterior and mediolateral direction and horizontal torsional destructive tests. Approaches to the humeral shaft should be dictated by the location of the fracture. The anterolateral exposure utilizing the deltopectoral interval with extension down the arm through a brachialis split provides excellent exposure to the proximal diaphysis. Distal extension is limited by the radial nerve piercing the lateral intermuscular septum. Posterior approaches facilitate exposure of distal third fractures and can be extended proximally with mobilization of the radial nerve from the spiral groove [10-16]

The aim of fixation with anterolateral approach is to decrease the rate of radial nerve injury with anteromedial plating as the anteromedial surface of humerus is smooth regular surface, also fixation helps patient to obtain pain free extremites, establish bone union with acceptable alignment and restore patient pre injury level of activity.

This study included 21 patients with humeral shaft fractures operated with anterolateral approach also with anteromedial plating. 18 patients developed full union within first 3 months while 3 patients developed full union within first 6 months, all of them were old age over 50 years old, one of them was obese, diabetic, hypertensive and one of them was smoker, so delayed to 6 months. In this approach there is guarantee of avoiding radial nerve injury with minimal soft tissue injury, also this leads to decrease risk of infection and nerve injury, also allow patient to rapid return to normal daily activities. 
In this study, the clinical results were graded as excellent in 14 patients $(66.6 \%)$, good in 4 patients $(19 \%)$, fair in 3 patients $(14.3 \%) \&$ poor in no patients $(0 \%)$. The excellent and good results were considered as satisfactory results while the unsatisfactory included the fair and the poor results. Thus, satisfactory results were found in 18 patients $(85.7 \%)$, and the unsatisfactory results were found in 3 patients $(14.3 \%)$.

In this study, 20 patients had no pain $(95.2 \%)$ and only one patient was suffering from pain at first 2 moths of follow-up (4.8\%). All patients developed full range elbow and returned rapidly to their normal daily $100 \%$ ) activity as fracture in 18 patient $(85.7 \%)$ was united within 3 months and fracture in 3 patient $(14.3 \%)$ was united within 6 months, all of them were old age over 50 years old, one of them was obese, diabetic, hypertensive and one of them was smoker.

In this study, the mean age of patients with excellent results was 28 years old and of patients with good results was 47 years old, while the mean age in patients with fair results was 51 years old. Studying the relation between different age groups and the results showed to be statistically significant.

In this study, in this study, there were 3 smokers (14.3)\%. One patient $(4.76 \%)$ of them had good final end results, two patient $(9.55 \%)$ had fair end results. Studying the relation between smoking and the final end results showed to be statistically significant.

In this study, there were 16 patients $(76.1 \%)$ who were males 11 patients had excellent result, 3 patients had good result (14.3\%) and 2 patients had fair result $(9.55 \%)$. Also there were 14 patients who were females 3 patients (14.3\%) had excellent final end results, one patients had good end results and one patient had fair end result $(4.76 \%)$. Studying the relation between smoking and the final end results showed to be statistically insignificant.

In this study, there were 8 patients $(38.09 \%)$ with transverse fracture 5 of them had excellent result (23.8\%), 1 patient of them had good result $(4.76 \%)$ and 2 patient had fair 6 patients $(28.5 \%)$ with oblique fracture 4 patients $(19.1 \%)$ of them had excellent result and 2 patients $(9.55 \%)$ of them had good result, 6 with spiral fracture 5 of them excellent result $(28.5 \%)$ and one of them $(4.76 \%)$ with good result and one with comminuted fracture who had fair result $(4.76 \%)$.

In this study, there were 6 patient $(28.5 \%)$ with road traffic accident 4 of them (19.1\%) were with excellent result 1 of them was good $(4.76 \%)$ and 1 was good result. Also there were 6 patient $(28.5 \%)$ with fall on out stretched hand 2 patiients $(9.55 \%)$ of them with excellent result, 2 patients were with good result $(9.55 \%)$ and 2 patients with fair result $(9.55 \%)$. Also there were 6 patient with direct trauma 5 patients of them with excellent result and 1 patient with good result (4.76\%). Also there were 3 patient $(14.3 \%)$ falling from height all of them with good result the final results showed it to be statistically insignificant.

In this study, there were 18 patients $(85.7 \%)$ with high demand occupations 12 patient of them $(57.1 \%)$ with excellent result, 4 patient's good result $(19.1 \%)$ t, 2 patients fair result $(9.55 \%)$. Also 3 patients $(14.3 \%)$ of them with low demand 2 patients $(9.55 \%)$ of them excellent result, one patient $(4.76 \%)$ fair result and the final end results showed to be statistically insignificant.

In this study, there were 11 patient $(52.3 \%)$ right sided 7 patients of them $(33.3 \%)$ with excellent result, 3 patients good $(14.3 \%), 1$ patient $(4.76 \%)$ fair, 10 patient left $(47.6 \%) \mathrm{t}$ sided 7 patients excellent result $(33.3 \%) 1$ patient good result $(4.76 \%)$, one patient fair the final results showed it to be statistically insignificant $(4.76 \%)$.

In this study, there were 3 patients obese (14.3\%) 1 patient with excellent $(4.76 \%), 1$ patient with good result $(4.76 \%), 1$ patient with fair (4.76\%), 18 patient non obese (85.7\%) 14 patients with excellent result (66.6\%), 4 patients with good result, 3 patients fair result $(14.3 \%)$ the final results showed it to be statistically insignificant.

In this study, 20 patient with no medical comorbidity (95.2\%) 14 patient of them with excellent result $(66.6 \%), 4$ patients good result $(19.1 \%), 2$ patients fair $(9.55 \%)$, one patient with medical comorbidity $(4.76 \%)$ with fair result the final results showed it to be statistically insignificant.

Liskutin, et al., [16] 2018, concluded that an anterolateral approach to the humerus offers excellent exposure to some humeral shaft fractures, particularly those that lie more proximally. However, they reported that its use must be done carefully against several other approach options, and the surgeon must account for the specific fracture pattern, as well as their own comfort and familiarity with the approach.

Kirin, et al., [17] 2011, concluded that an anteromedial plating of humeral shaft fractures through anterolateral approach was determind to be a simple, safe, effective and also fast surgical treatment 
and they highly recommend it as operative technique for treating humeral shaft fractures.

Zheng, et al., [15] 2016 concluded in their study that open reduction and internal fixation with plate and screws are the gold standard for the surgical treatment of humeral shaft fractures, this study was to compare the mechanical properties of anteromedial, anterolateral, and posterior plating for humeral shaft fractures. They concluded that anteromedial plating was superior to anterolateral or posterior plating in all mechanical tests except in AP four-point bending fatigue tests compared to the anterolateral plating group. They could suggest that anteromedial plating is a clinically safe and effective way for humeral shaft fractures.

Kumar et al., 2012 [18], concluded that internal fixation with various fixation devices allows early mobilization and good functional recovery. Operative treatment results with dynamic compression plate and interlocking nail were comparable in with some pits and fall in each technique, distraction, nerve injury, shoulder impingement, infection and implant failure. Implant choice depends upon indications, discussion with patient and choice of surgeon, which implant they want to use for internal fixation of these fractures. But Kumar et al., viewed that in well evaluated patients, where indications are clear choice for internal fixation with either implant is optimal management. Both plating and nailing has own its benefits and demerits. Which implant is more preferable, is not very conclusive and it needs more study and meta-analysis.

Yehia Elbassiony [19] 2016 and his colleagues concluded that lateral approach for the humerus is an excellent way for radial nerve exploration and for cases where the lateral, the anterior, and the posterior surfaces of the humerus needed to be approached simultaneously. This approach allows supine positioning of the multiply injured patients and proper visualization of the radial nerve without muscle splitting; however, it does not allow exploration of the radial nerve in the proximal third of the humerus.

Felipe fernandes goncalves [20] 2018 and his collages concluded that the main surgical treatments for humeral shaft fractures are ORIF with plate and screws, minimally invasive technique with bridge plating, and IMN. Their study, it was observed that all methods presented high rates of consolidation, with few reported complications, proving to be suitable options for the surgical treatment. External fixatiors were the definitive method of treatment in some cases of high-energy trauma, presenting a high rate of pseudoarthrosis. This incidence may be related to the type of fracture and adjacent soft tissues lesions, but the present sample did not include enough cases to allow a definitive conclusion.

Lu et al., [21] 2016 concluded that the medial plating to the humerus had equivalent outcomes to anterolateral fixation. It is available choice for humeral mid-shaft fracture fixation in cases where there is no need to expose the radial nerve. The medial plating does not require a pre-bent plate and creates a large operative exposure. A wellhidden incision can also be designed, improving cosmetic outcomes. However, the medial approach is not suitable to proximal or distal humerus fractures. The advantage of the anteromedial plating observed in the present study are avoidance of radial nerve dissection, deltoid tendon release and the stress of shielding of the plate with mega breast in female.

\section{References}

1- KUMAR B.S., SORAGANVI P. and SATYARUP D.: Treatment of Middle Third Humeral Shaft Fractures with anteromedial plate osteosynthesis through an anterolateral approach-Malays Orthop. J., Mar., 10 (1): 38-43, 2016.

2- McMINN R.M.H.: Upper limb, osteology of humerus. In McMinn R, M.H. (eds): Last's Anatomy. Regional and Applied. Eighth edition British government ELBS with Churchill Livingstone, 131-4, 1990.

3- GOTTSCHALK M., CARPENTER W., HIZA E., REISMAN W. and ROBERSON J.: Humeral Shaft Fracture Fixation: Incidence Rates and Complications as Reported by American Board of Orthopaedic Surgery Part II Candidates. The Journal of bone and joint surgery. American volume, Vol. 98, Issue 17, p. e71, 2016.

4- McKEE M.D.: Fractures of the shaft of the humerus. In: Bucholz R.W., Heckman J.D., Court-Brown C.M. (eds) Rockwood and Green's fractures in adults, Vol. 1, $6^{\text {th }}$ edition. Philadelphia, Lippincott, Williams \& Wilkins. 1117-59, 2006.

5- DAYEZ J.: Medial plating for treatment of recent fractures of humeral shaft. Chir. Orthop., 85: 238-44, 1999.

6- HOLESTIN A. and LEWIS G.B.: Fractures of the humerus with radial nerve paralysis. J. B. J. Surg., 45A. 1382-8, 1963.

7- SARMIENTO A., ZAGROSKI and JBMZYCH G.A.: Functional bracing for the treatment of fractures of the humeral diaphysis J. Bone Joint. Surg., (Am.) 82-A: 47886, 2000.

8- WALKER M., PALUMBO B., BROOKS J., GELDEREN J.V. and MIGHELL M.: Humeral shaft fractures: A review. J. Shoulder Elbow Surg., 20 (5): 833-44, 2011.

9- SINGISETTI K. and AMBEDKAR M.: Nailing versus plating in humeral shaft fractures-A prospective comparative study. International Orthop. (SICOT)., 34: 571-6, 2010. 
10- In HYEOK RHYOU, JI-HO LEE, KYUNG CHUL KIM, KEEBAEK AHN, SEONGCHEOL MOON, HYEONG JIN KIM and JUNG HYUN LEE: Management of humeral shaft fractures Clin. Orthop. Relat. Res., Sep., 475 (9): 2308-15. Published online 2017 Apr. 12, 2017.

11-LIVANI B., BELANGERO W., MEDINA G., PIMENTA C., ZOGAIB R. and MONGON: Anterior plating as a surgical alternative in the treatment of humeral shaft nonM. International Orthopaedics, Vol. 34, Issue 7, pp. 102531, 2010.

12- Mc CORMACK R.G., BRIEN D. and BUCKCLY R.E.: Fixation of fractures shaft of the humerus by dynamic compression plate or intramedullary nail A prospective, randomized trail. J. Bone Joint Sur. (Br.), 82-B 36, 2000.

13- ZLOTOLOW D.A., CATALANO L.W., $3^{\text {rd }}$, BARRON O.A., et al.: Surgical exposures of the humerus. J. Am. Acad. Orthop. Surg., 14: 754-65, 2006.

14- ZHENG J., JUN-LIN Z., XIAO-HONG W., LEI SHAN and YANG LIU: Biomechanical study of fixation strength of anteromedial plating for humeral shaft fractures, Chin. M. J., 15 Vol. 129:1850-5, 2016.

15- JIANG R., LUO C.F., ZENG B.F., et al.: Minimally invasive plating for complex humeral shaft fractures. Arch. Orthop. Trauma Surg., 127: 531-5, 2007.

16- LISKUTIN T., HOBIE SUMMERS, WILLIAM LACK, MITCHELL BERNSTEIN, et al.: Surgical Technique:
Anterolateral Approach to the Humerus. J. Orthop. Trauma, 11: 536-9, 2018.

17- KIRIN I., JURISIC D., GREBIC D. and NADALIN S.: The advantages of humeral anteromedial plate osteosynthesis in the middle third shaft fractures. Middle East J. Med., 123 (3-4): 83-7, 2011.

18- KUMAR R., PANKAJ, SINGHM LAL, JEE CHAUD HARY and SHAILENDRA: Singh: Humeral shaft fracture management, a prospective study; nailing or plating. J. Clin. Orthop. Trauma, Jun., 3 (1): 37-42, 2012.

19-ELBASSIOUNY Y. and ELGOHARY H.: Lateral approach to the humeral shaft: Approach for special situations. Eygptian Orthop. J., Vol. 51 p. 180-5, 2016.

20- FELIPE G., LEONARDO D., CRISTIANO G., FABIANO P., AYRTON M. and PATRÍCIA P. ORTOP: Evaluation of the surgical treatment evaluation of the surgical treatment of humeral shaft fractures and comparsion between surgical fixation methods. Mar.-Apr., 53 (2): 136-41, 2018.

21- SHUN LU, JUNWEI XU, BAISHENG FU, JINLEI D., YONGLIANG Y., GUODONG WANG, MAOYUAN X., QINGHU L., TONG-CHUAN H., FU WANG and DONG SHENG Z.: Evaluation of the surgical treatment of humeral shaft fractures and comparison between surgical fixation methodsMedial approach to treat humeral mid-shaft fractures: A retrospective study J. Orthop. Surg. Res., 11: 32, 2016. 


\section{تثبيت كسور المحور العضلدى الأوسط الثالث

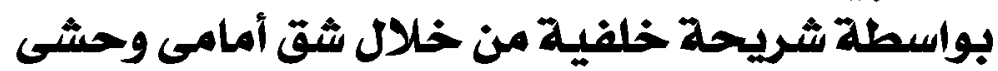

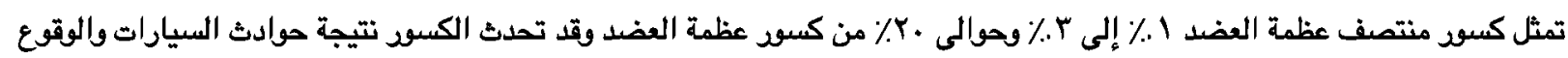

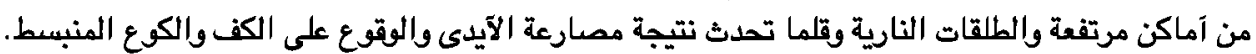

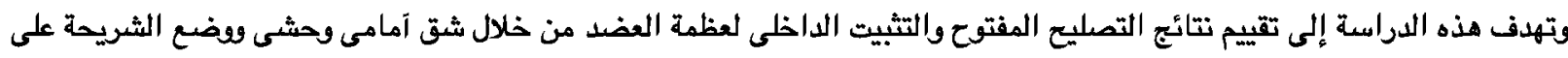

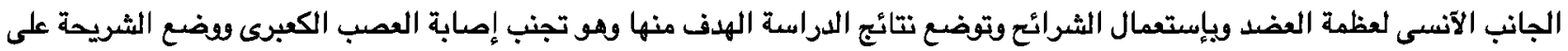
الجهة الآنسية المستوية وذلك آفضل سطح منتظم لوضع الشريحة مع الحفاظظ على العضلات والآنسجة وقوقت جراحى آقل.

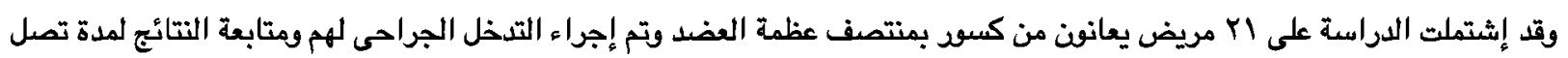

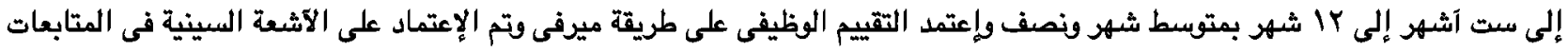

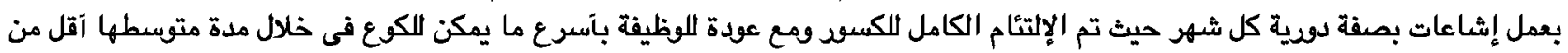
r آشهر وعودة المريض لآنشطته اليومية ومع الحفاظ على وظيفة العصب الكعبرى.

وتم تقييم النتائج وفقاً لوقت إلتحام الكسود حيث تم إلتحام جميع الكسود فى مدة آتل من 7 آشهر ومن خلال تقييم وظيفة مفصل الكوع

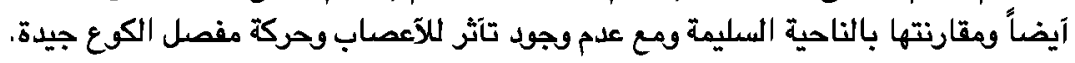

النتائج الوظيفية:

$$
\begin{aligned}
& \text { • ممتازة } 7.797 .
\end{aligned}
$$

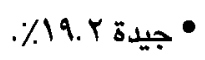

$$
\begin{aligned}
& \text { • مقبولة r. }
\end{aligned}
$$

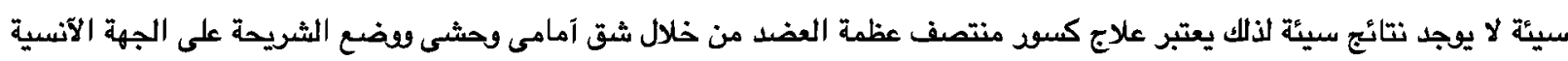
طريقة جيدة لتقليل إصابة العصب الكعبرى والحفاظ على آنسجة العضلات ومع وجود نتائج جيدة وعودة المرضى لآنشطتهم اليومية بطريقة الإستتاج: نستنتج من ذالك آن تثبيت كسود منتصف عظمة العضد من خلال شق آمامى وحشى يساعد فى الحفاظ على العصب الكعبرى ويحافظ على عضلات وآنسجة الكتف وآمن. 